\title{
Pessary use in stress urinary incontinence: a review of advantages, complications, patient satisfaction, and quality of life
}

This article was published in the following Dove Press journal: International Journal of Women's Health

\author{
Ghadeer Al-Shaikh' \\ Sadiqa Syed ${ }^{2}$ \\ Somaia Osman ${ }^{3}$ \\ Abdulrahman Bogis' \\ Ahmed Al-Badr ${ }^{3}$ \\ 'Department of Obstetrics and \\ Gynecology, College of Medicine, King \\ Saud University, Riyadh, Saudi Arabia; \\ ${ }^{2}$ Department of Basic Sciences, \\ College of Medicine, Princess \\ Nourah bint Abdulrahman University, \\ Riyadh, Saudi Arabia; ${ }^{3}$ Department \\ of Urogynecology \& Pelvic \\ Reconstructive Surgery, Women's \\ Specialized Hospital, King Fahad \\ Medical City, Riyadh, Saudi Arabia
}

\begin{abstract}
Stress urinary incontinence (SUI) is a common condition among women. The usual approach to treatment of SUI is a stepwise plan from conservative to surgical procedures. A vaginal pessary is one of the commonly used conservative treatments that offer symptomatic improvement for women with incontinence. This review provides a critical analysis of the benefits and shortcomings offered by vaginal pessaries to patients affected by SUI, with a particular focus on indications, advantages, quality of life, patient satisfaction, and potential complications. To obtain the required information, an extensive search of PubMed and Cochrane databases was performed, covering the time frame from January 2000 to December 2016. We also surveyed the published guidelines of American Urological Association, Canadian Urological Association, American Urogynecological Society, National Institutes of Health (USA), and National Institute for Health and Care Excellence (UK). A total of 192 original research papers, review articles, and clinical trials were identified. The analysis of retrieved data provides evidence that vaginal pessaries constitute an effective nonsurgical option for SUI. The satisfaction rate with pessary use is high and only minor complications, if any, occur, vaginal discharge being the most common. The reviewed studies document that vaginal pessaries provide an adequate control of SUI if they are fit properly and managed by frequent replacements and regular checkups. They should be considered among the first line of treatment for SUI associated with exercise and increased intra-abdominal pressure.
\end{abstract}

Keywords: pessary, urinary incontinence, nonsurgical intervention, vaginal prolapse

\section{Introduction}

Stress urinary incontinence (SUI) is an involuntary loss of urine on effort, physical exertion, or with an increase in the intra-abdominal pressure upon sneezing or coughing. This common and embarrassing condition affects 200 million people worldwide with the median prevalence of female urinary incontinence (UI) being $27.6 \%$ (range: $4.8 \%-58.4 \%)^{2}$. According to the 2010 International Urogynecological Association, the prevalence of SUI is age-dependent and ranges from $29 \%$ to $75 \%$ with a mean of $48 \%{ }^{3}$ It is more common in the younger age group, but it also occurs in older women. The prevalence of daily SUI is $10 \%$ in community-dwelling middle-aged women, ${ }^{4}$ and a third of women with SUI report weekly leakage. ${ }^{5}$ Each year, approximately 135,000 women undergo surgery for SUI in the USA alone; approximately $11 \%$ undergo surgery for SUI by 80 years of age. ${ }^{6}$ The risk factors for SUI include obesity, menopause, number of pregnancies and vaginal deliveries, use of medications relaxing the urethral sphincter, presence of a lung disease causing chronic cough, and prior pelvic surgeries. ${ }^{7,8}$

\footnotetext{
Korrespondence: Ghadeer Al-Shaikh Rd, P. O. Box 2454, King Khalid Saudi Arabia

Tel +966530044090

Fax $+966 \quad 14679557$

Email ghadeer-alshaikh@hotmail.com
} 
SUI often remains undetected and undertreated. ${ }^{9}$ The underlying reasons include the reluctance of patients to disclose their incontinence and urinary symptoms due to embarrassment, lack of knowledge about treatment options, fear of surgery, or belief that SUI is an inevitable part of aging. ${ }^{10} \mathrm{In}$ one survey, only $22 \%$ of men and $45 \%$ of women experiencing weekly incontinence sought medical care. ${ }^{11}$ Only $60 \%$ of them received treatment for their incontinence and nearly $50 \%$ of treated patients reported continued incontinence. ${ }^{11}$

Although SUI is not associated with increased mortality, it affects many aspects of a patients' health such as physical activity, social contacts, sexual contacts, emotional state, sleep, physical, psychosocial and economic well-being as well as health-related quality of life (QoL). ${ }^{12}$ SUI adversely impacts QoL by contributing to depression, anxiety, social isolation, and even admission to a nursing home. ${ }^{13,14}$ Moreover, incontinence during sexual activity affects up to onethird of patients, and fear of UI during intercourse contributes to sexual dysfunction. ${ }^{15}$

Clinically, SUI is present alone or in association with pelvic organ prolapse (POP).$^{16} \mathrm{~A}$ majority of the published research is focused on the use of pessaries in POP, on comparison of effectiveness of multiple modalities of conservative treatments with one another or with surgical methods in patients with SUI. The objective of the present review is to assess three distinct patient-oriented outcomes of pessary use: advantages, complications, and QoL.

\section{Methods}

A search of PubMed and Cochrane Library databases was performed, using the records from January 2000 to December 2016. The queries used MeSH terms "stress urinary incontinence," "conservative management," "pessary," "behavioral treatment," and "clinical practice guidelines." Guidelines of the American Urological Association, Canadian Urological Association, American Urogynecological Society, National Institutes of Health (USA), and National Institute for Health and Care Excellence (UK) were also surveyed. A total of 192 original research papers, review articles, and clinical trials were identified. We selected a total of 62 relevant prospective cohort studies, randomized controlled trials (RCTs), and review articles addressing prevalence of UI, management options, fitting, and efficacy of pessary in management of UI, to provide this update on pessary use in SUI. We eliminated 130 articles because of irrelevance or duplicity.

\section{Treatment options}

The treatment plan should be discussed with the patients with emphasis on improving QoL. The typical approach to treatment of SUI is a stepped care plan that starts with noninvasive behavioral modifications followed by devices and pharmacologic interventions. Surgery is the final step for women having symptoms that do not respond to initial treatment. ${ }^{17}$

The conservative management of SUI includes, in approximate order of priority, weight loss, smoking cessation, constipation management, pelvic floor muscle exercises, extracorporeal magnetic innervation, electrical stimulation, and mechanical devices such as a pessary or urethral plug. ${ }^{18,19}$ As an example, it has been reported that exercise-mediated reduction of weight by only $8 \%$ resulted in a nearly $50 \%$ decrease in the frequency of incontinence episodes. ${ }^{20}$ Additionally, cessation of drugs like $\alpha$-adrenergic receptor blocker may also improve the condition. ${ }^{21}$ Furthermore, analysis of relevant publications indicated that the two most frequently described and systematically investigated conservative treatment options are behavioral therapy with pelvic floor muscle training (PFMT) and the use of intravaginal support devices such as incontinence pessaries. ${ }^{22}$ In fact, the guidelines of the Dutch College of General Practitioners recommend that women with SUI are offered a choice between PFMT and a pessary as initial treatment; a mid-urethral sling should only be discussed when initial treatment is insufficient or in case with severe symptoms. ${ }^{23}$

PFMT and continence strategies such as timed voiding and volitional contraction of pelvic floor muscles before and during a cough (the Knack maneuver) have been shown to help in the prevention of incontinence. ${ }^{24,25}$ Significantly, Kegel exercises should be done several times a day and performed consistently over time to obtain sustained benefits. ${ }^{26} \mathrm{How}-$ ever, it has been pointed out that the key problem negatively affecting continuity of PFMT exercises is the lack of patient motivation and inconsistency in their execution. ${ }^{27}$ Additionally, a systematic review of 23 clinical trials demonstrated that a significant reduction in SUI can be achieved with PFMT and found that the benefits can be further enhanced if combined with bladder training. ${ }^{28}$ In contrast, the search of the Cochrane database did not find adequate evidence to recommend or discourage behavioral strategies such as timed voiding, habit retraining, and prompted voiding. ${ }^{29}$

Vaginal pessary is one of the oldest medical devices and has been used for centuries as a conservative treatment of $\mathrm{POP}^{30}$ and, more recently, for SUI. ${ }^{31}$ Once a decision to use a pessary is made, the type of pessary should be chosen based on the severity of SUI, presence of prolapse, and sexual activity. Incontinence pessaries are silicone or rubber devices that are placed transvaginally. They are designed to support the urethra and bladder wall, increase urethral length, and provide gentle compression of the urethra against the pubic bone. 
This structural arrangement reduces and often prevents leakage when intra-abdominal pressure increases, essentially resolving the problem of incontinence. ${ }^{32,33}$ From this position, an incontinence pessary supports the urethrovesical junction in the same way a vaginal sling implanted surgically would. ${ }^{34}$

Different types of pessaries are available, and some have been designed specifically to treat SUI. The latter group includes incontinence ring pessary, ring pessary with support (common size 2-7, characterized by ease of insertion), incontinence dish (common size 3-5, medium ease of insertion and removal), and the Uresta device. All of them exert their action by stabilizing the urethra and increasing urethral resistance. ${ }^{35}$ Incontinence rings and dish pessaries, most commonly used in patients with SUI, are typically made of silicone. A Hodge pessary without support (for a small cystocele) or with support (in the absence of cystocele) can also be used. Introl, a bladder neck support prosthesis, supports the urethrovesical junction and was found to be effective in $83 \%$ of adult women with SUI. ${ }^{36}$ The self-positioning women's incontinence pessary (Uresta) also significantly reduces UI, is easy for women to use, and has a high continuation rate of $76 \%$ in the first year. ${ }^{37}$

\section{Indications and contraindications for pessary use}

Pessaries should be considered for all women presenting with SUI, in particular when conservative management is appropriate. Excellent candidates for pessary use include pregnant patients, elderly women for whom surgery would be a risk, and women in whom a previous operation for SUI have failed. Additionally, pessaries are a valid option for patients who only have SUI with strenuous physical activity. ${ }^{38}$ Although their use is not recommended by the National Institute for Health and Care Excellence, UK, due to limited high quality evidence, ${ }^{39}$ the rate of application is increasing due to low cost, ease of use, and infrequent side effects. ${ }^{40}$

There are very few contraindications for pessary use, allowing clinicians to offer pessaries to almost all patients presenting with prolapse and incontinence. However, a pessary should not be placed in a patient with evidence of active pelvic or vaginal infection, severe ulceration, allergy to silicone or rubber, and patients who are noncompliant and unlikely to follow-up. ${ }^{41}$

\section{Successful pessary fitting and continued use}

Pessary fitting has long been considered an art rather than a science, a process of trial and error whereby a clinician's training and experience is the best predictor. A pessary must be fit by a health care provider, as many women require more than one fitting to achieve comfort. Before pessary fitting, the patients' bladder should be emptied, and the clinician should estimate the width of the mid-vagina and select a pessary of appropriate size. The patient should then be fit with the largest pessary that fits comfortably and examined in the supine and standing positions. ${ }^{41}$ Proper size and adequate fitting is achieved when the provider can place a finger between the pessary and the vaginal wall. ${ }^{42}$ Successful fitting is defined as a comfortable fit with retention of the pessary during the Valsalva maneuver and voiding. Continuation is declared if a successfully fit patient returns at least once after the initial fitting with the pessary still in use. ${ }^{43}$ An ideal situation is when a woman can place her pessary at times when she anticipates urine leakage such as during exercise. Ideally, a pessary should be inert, compact, and relatively inexpensive; its design should allow easy removal and insertion by the patient. Following a successful fitting, the patient should be seen within 2-4 weeks for proper instruction for removal and self-care. The importance of proper pessary fitting is highlighted by the finding that a higher continuation rate, $90 \%$, is achieved in patients with successful fitting. ${ }^{44}$

A pessary fitting is considered unsuccessful if the provider fails to obtain an adequate fit after at least three attempts or the patient finds the pessary painful and intends to discontinue its use. ${ }^{42}$ The causes for unsuccessful fittings include a widened genital introitus (four fingers breadth), a short vaginal length of $<6 \mathrm{~cm}$, and posterior compartment defects. ${ }^{45}$

Multicenter studies reported 89\%-92\% success rate for fitting pessaries in women with SUI. ${ }^{40,42}$ However, the population of women using a pessary for SUI is younger, less likely to have had previous surgery, and have a longer vaginal length than the population with prolapse.

A prospective cohort study documented that the rate of initial successful fitting varies between $60 \%$ and $92 \%$ with an incontinence ring, ${ }^{42,46}$ but the continued use decreases to $55 \%$ in 6 months and $16 \%$ in 1 year. ${ }^{47}$ It is, however, noteworthy that the study on continued use employed a ring with a diaphragm, a pessary known for its low efficacy. ${ }^{47}$ A retrospective review ${ }^{48}$ reported that $59 \%$ of women continued the use of pessaries at 11 months, reporting a resolution or decrease of their incontinence. The reasons for discontinuation included persistent incontinence, discomfort, bleeding, and repeated expulsions. ${ }^{48}$ Another study indicated that $86 \%$ of women referred to a dedicated midwifery pessary clinic were successfully fit and $89 \%$ continued pessary use for a mean of 6 months. Predictors of unsuccessful fitting 
included a history of a prolapse procedure or hysterectomy, while severe posterior prolapse was the single predictor of pessary discontinuation. ${ }^{49}$

\section{Advantages of pessary use}

Pessaries constitute a good option for treatment of incontinence for women in any age group. They have the distinct advantage of being minimally invasive while providing immediate relief of symptoms. Their associated risks and costs are low and they achieve results quickly. Furthermore, they may be controlled by the patients themselves, are an excellent alternative for symptomatic women who have not finished childbearing, and those who choose a nonsurgical intervention. ${ }^{50}$ Additionally, a recent study comparing the cost of nonsurgical with surgical treatment for SUI found that an incontinence pessary was the most cost-effective treatment option. ${ }^{51}$

The pessary can also be used to distinguish between patients with SUI secondary to a correctable anatomic defect or bladder instability. A properly fit pessary can simulate the result of surgical correction of incontinence, thereby yielding diagnostic and prognostic information. ${ }^{38}$ Moreover, a pessary is a better option than an urethral plug inserted into the urethra to prevent urine loss; the latter is associated with a number of adverse events, including urinary tract infection, hematuria, and migration into the bladder. ${ }^{52}$ Since no medication is approved by the US Food and Drug Administration for the treatment of SUI in the United States, pessaries have become the ultimate choice for both younger and older patients as well as those avoiding surgery or waiting for surgery. ${ }^{53}$ However, while certain drugs such as duloxetine, marketed as Cymbalta, is approved for use in Europe for the treatment of SUI, it has recently been demonstrated to cause more harm than benefit. ${ }^{54}$

Results of a survey conducted by the International Urogynecological Association ${ }^{55}$ regarding practice patterns in women with SUI indicated that $61.5 \%$ of medical practitioners worldwide always or frequently offer a pessary to patients with SUI associated with POP. No difference was found among these practitioners in their academic affiliation. However, significant regional differences were present; the number of providers prescribing a pessary was highest in North America and lowest in Africa. ${ }^{55}$ It is worth noting that this percentage was significantly higher $(52 \%, p=0.008)$ than that noted in 2013. Other studies reported that pessaries are being used in daily practice by $86 \%$ of gynecologists and $98 \%$ of urogynecologists. ${ }^{56,57}$

The Canadian Urological Association guidelines also recommend pessaries be considered in initial management of
SUI, along with PFMT. ${ }^{58}$ An RCT with 446 women enrolled found that, at 3 months, women using pessary alone had a $40 \%$ improvement compared to $49 \%$ with behavioral therapy. However, at 12 months, $32 \%$ of the participants showed improvement in both groups. ${ }^{57}$

\section{Patient satisfaction and QoL}

The role of pessaries for UI has changed in the past few years when family physicians have begun to utilize pessaries inpatient care. ${ }^{29}$ Currently, satisfaction rates with pessary use have become higher and is the reason why the pessary is experiencing a resurgence in popularity. ${ }^{50} \mathrm{~A}$ prospective study documented that $92 \%$ of women with a successful pessary fitting for POP were satisfied with treatment after 2 months and their urinary symptoms were reduced by $50 \% .{ }^{59}$ Additionally, a secondary analysis of a multicenter, randomized trial (ATLAS) reported no difference in pelvic symptom bother and QoL between pessary and behavioral therapy treatments and showed similar patient satisfaction after 3 months. ${ }^{60}$ This study confirmed that frequency, bother, and QoL improve 3 months after either behavioral or pessary treatment. Contrasting results have been obtained regarding the impact of pessaries on sexual function. In one study, a greater improvement was seen among women treated with behavioral therapy than those treated with pessary. ${ }^{61}$ On the other hand, a significant improvement in both frequency and satisfaction among sexually active women who wear a pessary was also reported. ${ }^{62}$ Also, another study documented that $60 \%$ of sexually active women who accepted a pessary for SUI or POP continue treatment for an extended period. ${ }^{63}$

Studies have also been performed comparing the effectiveness of pessary with that of behavioral therapy. An RCT reported that $75 \%$ of women were satisfied with behavioral therapy, while only $33 \%$ were satisfied with a pessary at 3 months, but at 12 months the success rate declined in both groups and the statistically significant difference in outcome between the two groups was no longer present. ${ }^{57}$ Another study reported predictors of success and satisfaction for behavioral therapy and pessary treatment after 3 months. ${ }^{64}$ This study identified several predictors of successful therapy: severity of stress symptoms, $<14$ weekly episodes of UI, college education, and no previous history of UI surgery. Moreover, postmenopausal women reported a greater improvement in their continence status than premenopausal women; physical activity and body weight may have a significant impact on muscle structure and function even in postmenopausal women who are thought to undergo a decline in muscle strength. ${ }^{64}$ 
The outcomes of pessaries and surgery in women with symptomatic POP were also studied using validated questionnaires. This investigation reported equal improvement in vaginal, urinary, bowel, and QoL scores, regardless of whether the treatment involved a pessary or surgery ${ }^{65}$ Although recent studies show significant improvement in SUI with the use of a pessary, ${ }^{44}$ younger, sexually active women with more severe symptoms either opt for surgery initially or escalate their treatment from conservative to surgical. ${ }^{66}$ Another indication for surgical intervention is the case of women who have underwent a hysterectomy or other pelvic surgeries, where these procedures predispose to weakness of the pelvic floor and subsequently the inability to retain a pessary. ${ }^{49}$

\section{Complications}

Currently available pessaries are composed of inert substances that require minimal care, regular removal, and inspection of vaginal epithelium. ${ }^{67}$ Common complications include vaginal discharge and odor, new onset difficulty in voiding, spontaneous expulsion, and more rarely, vaginal erosion due to a forgotten or neglected pessary. ${ }^{38}$ Minor complications such as vaginal discharge, odor, and erosion can usually be successfully treated. More severe complications were reported after long-term (6-10 years) use of pessaries in patients with prolapse. They included bleeding, severe vaginal discharge, pain, and constipation; $23 \%$ of women had more than one type of complication and most had more than one episode. ${ }^{68}$ Treatment of these complications includes local administration of estrogen, regular follow-up, and appropriate fitting of the pessary.

\section{Conclusion}

Vaginal pessaries are very effective at managing SUI if they are fit properly and managed by frequent removals and regular checkups. They should be considered among first line of treatment of SUI associated with exercise and increased intra-abdominal pressure. For SUI with POP, a pessary may also be considered as the management of choice, together with educating patients on the technique of insertion and removal and the volitional contraction of pelvic muscles. Satisfaction rate with pessary use is high, and, if any, only minor complications occur, with vaginal discharge being the most common complaint.

\section{Acknowledgment}

To the College of Medicine Research Center, Deanship of Scientific Research, King Saud University, Riyadh, Saudi Arabia for supporting this research.

\section{Disclosure}

The authors report no conflicts of interest in this work.

\section{References}

1. Haylen BT, deRidder D, Freeman RM, et al. An International Urogynecological Association (IUGA)/International Continence Society (ICS) joint report on the terminology for female pelvic floor dysfunction. Int Urogynecol J. 2010;21:5-26.

2. Minassian VA, Drutz HP, Al-Badr A. Urinary incontinence as a worldwide problem. Int J Gynecol Obstet. 2003;82:327-338.

3. Hunskaar S, Burgio K, Diokno A, Herzog AR, Hjälmås K, Lapitan MC. Epidemiology and natural history of urinary incontinence in women. Urology. 2003;62(Suppl 1):16-23.

4. Swift S, Woodman P, O'Boyle A, et al. Pelvic organ support study (POSST): the distribution, clinical definition and epidemiologic condition of pelvic organ support defects. Am J Obstet Gynecol. 2005;192: 795-806.

5. Nygaard IE, Heit M. Stress urinary incontinence. Obstet Gynaecol. 2004; 104:607-620.

6. Waetjen LE, Subak LL, Shen H, et al. Stress urinary incontinence surgery in United States. Obstet Gynecol. 2003;101:671-676.

7. Stewart E. Treating urinary incontinence in older women. Br J Community Nurs. 2010;15:526-532.

8. DeMaagd GA, Davenport TC. Management of urinary incontinence. Pharm Therap. 2012;37:345-361.

9. Abrams P, Cardozo L, Fall M, et al. The standardisation of terminology of lower urinary tract function: report from the Standardisation Subcommittee of the International Continence Society. Neurourol Urodyn. 2002;21:167-178.

10. Cheater FM, Castleden CM. Epidemiology and classification of urinary incontinence. Baillieres Best Pract Res Clin Obstet Gynaecol. 2000; 14:183-205.

11. Harris SS, Link CL, Tennstedt SL, Kusek JW, McKinlay JB. Care seeking and treatment of urinary incontinence in a diverse population. J Urol. 2007;177:650-654.

12. Ptak M, Brodowska A, Ciećwież S, Rotter I. Quality of life in women with stage 1 stress urinary incontinence after application of conservative treatment- a randomized trial. Int J Environ Res Public Health. 2017;14(6):pii E577.

13. Dubeau CE, Simon SE, Morris JN. The effect of urinary incontinence on quality of life in older nursing home residents. J Am Geriatr Soc. 2006;54:1325-1333.

14. Coyne KS, Sexton CC, Irwin DE, Kopp ZS, Kelleher CJ, Milsom I. The impact of overactive bladder, incontinence and other lower urinary tract symptoms on quality of life, work productivity, sexuality and emotional well-being in men and women: results from the EPIC study. BJU Int. 2008;101:1388-1395.

15. Serati M, Salvatore S, Uccella S, Nappi RE, Bolis P. Female urinary incontinence during intercourse: a review on an understudied problem for women's sexuality. $J$ Sex Med. 2009;6:40-48.

16. Buchsbaum GM. Urinary incontinence and pelvic organ prolapse. Minerva Urol Nefrol. 2006;58:311-319.

17. Hersh L, Salzman B. Clinical management of urinary incontinence in women. Am Fam Physician. 2013;87:634-640.

18. Norton P, Brubaker L. Urinary incontinence in women. Lancet. 2006 367:57-67.

19. Gibbs CF, Johnson TM II, Ouslander JG. Office management of geriatric urinary incontinence. Am J Med. 2007;120:211-220.

20. Subak LL, Wing R, West DS, et al. Weight loss to treat urinary incontinence in overweight and obese women. $N$ Engl J Med. 2009;360: $481-490$.

21. Khan IJ, Tariq SH. Urinary incontinence: behavioral modification therapy in older adult. Clin Geriatr Med. 2004;20:499-509.

22. McIntosh L, Anderson E, Reekie M. Conservative treatment of urinary stress incontinence in women: a 10-year (2004-2013) scoping review of the literature. Urol Nurs. 2015;35:179-186. 
23. Daman-Van Beek Z, Teunissen D, Dekker JH, et al. Practice guidelines 'urinary incontinence in women' from the Dutch College of General Practitioners. Ned Tijdschr Geneeskd. 2016;160:D674.

24. Miller J, Ashton-Miller J, Delancey J. A pelvic muscle precontraction can reduce cough related urine loss in selected women with mild SUI. J Am Geriatr Soc. 1998;46:870-874.

25. Miller J, Sampselle C, Ashton-Miller J, Hong G, Delancey J. Clarification and confirmation of Knack maneuver: the effect of volitional pelvic floor muscle contraction to preempt expected stress incontinence. Int Urogynecol J Pelvic Floor Dysfunct. 2008;19:773-782.

26. Dumoulin C, Hay-Smith J. Pelvic floor muscle training versus no treatment or inactive control treatment for urinary incontinence in women. Cochrane Database Syst Rev. 2010;(1):CD005654.

27. Borello-France D, Burgio KL, Goode PS, et al. Adherence to behavioral interventions for stress incontinence: rates, barriers, and predictors. Phys Ther. 2013;93:757-773.

28. Shamliyan T, Kane R, Wyman J, Wilt T. Systematic review: randomized controlled trials of non-surgical treatments for urinary incontinence in women. Ann Intern Med. 2008;148:459-473.

29. Frank C, Szlanta A. Office management of urinary incontinence among older patients. Can Fam Physician. 2010;56:1115-1120.

30. Shah SM, Sultan AH, Thakar R. The history and evolutions of pessaries for pelvic organ prolapse. Int Urogynecol J Pelvic Floor Dysfunc. 2006; 17:170-175.

31. Nygaard I. Prevention of exercise incontinence with mechanical devices. J Reprod Med. 1995;40:89-94.

32. Wood LN, Anger JT. Urinary incontinence in women. BMJ. 2014; 349:g4531.

33. Karon S. Conservative management of continence in women over the age of 65 years living in the community: a review. Aust NZ Cont J. 2009; $15: 34-44$.

34. Roehl B, Buchanan EM. Urinary incontinence evaluation and the utility of pessaries in older women. Care Manag J. 2006;7:213-217.

35. Komesu YM, Ketai LH, Rogers RG, Eberhardt SC, Pohl J. Restoration of continence by pessaries: magnetic resonance imaging assessment of mechanism of action. Am J Obstet Gynecol. 2008;198:563-566.

36. Towbridge ER, Fenner DE. Practicalities and pitfalls of pessaries in older women. Clin Obstet Gynecol. 2007;50:709-719.

37. Farrell SA, Baydock S, Amir B, Fanning C. Effectiveness of a new self-positioning pessary for the management of urinary incontinence in women. Am J Obstet Gynecol. 2007;196:474.e1-474.e8.

38. Viera AJ, Larkins-Pettigrew M. Practical use of the pessary. Am Fam Physician. 2000;61:2719-2726.

39. National Institute for Health and Care Excellence (NICE) [webpage on the Internet]. Urinary Incontinence: The Management of Urinary Incontinence in Women. CG171. London: Royal College of Obstetricians and Gynaecologists; 2013. Available from: www.nice.org.uk/ Guidance/CG171. Accessed August 6, 2017.

40. Donnelly MJ, Powell-Morgan S, Olsen AL, Nygaard IE. Vaginal pessaries for the management of stress and mixed urinary incontinence. Int Urogynecol J Pelvic Floor Dysfunct. 2004;15:302-307.

41. Jones KA, Harmanli O. Pessary use in pelvic organ prolapse and urinary incontinence. Rev Obstet Gynecol. 2010;3:3-9.

42. Nager CW, Richter HE, Nygaard I, et al. Incontinence pessaries: size, POPQ measures, and successful fitting. Int Urogynecol J. 2009;20: 1023-1028.

43. Cameron AP, Jimbo M, Heidelbaugh JJ. Diagnosis and office based treatment of urinary incontinence in adults. part two: treatment. Ther Adv Urol. 2013;5:189-200.

44. Ding J, Chen C, Song XC, Deng M, Zhu L. Changes in prolapse and urinary symptoms after successful fitting of a ring pessary with support in women with advanced pelvic organ prolapse: a prospective study. Urology. 2016;87:70-75.

45. Hanson LA, Schulz JA, Flood CG, Cooley B, Tam F. Vaginal pessaries in managing women with pelvic organ prolapse and urinary incontinence: patients characteristics and factors contributing to success. Int Urogynecol J Pelvic Floor Dysfunct. 2006;17:155-159.
46. Noblett KL, McKinney A, Lane FL. Effects of the incontinence dish pessary on urethral support and urodynamic parameters. Am J Obstet Gynecol. 2008;198:592.e1-592.e5.

47. Robert M, Mainprize TC. Long term assessment of incontinence ring pessary for the treatment of stress incontinence. Int Urogynecol J Pelvic Floor Dysfunct. 2002;13:302-307.

48. Farrell SA, Singh B, Aldakhil I. Continence pessaries in the management of urinary incontinence in women. J Obstet Gynecol Can. 2004;26: 113-117.

49. Maito JM, Quam ZA, Craig E, Danner KA, Rogers RG. Predictors of successful pessary fitting and continued use in a nurse-midwifery pessary clinic. J Midwifery Womens Health. 2006;51:78-84.

50. Robert M, Schulz JA, Harvey MA. Technical update on pessary use. J Obstet Gynecol Can. 2013;35:664-667.

51. Von Bargen E, Patterson D. Cost utility of the treatment of stress urinary incontinence. Female Pelvic Med Reconstr Surg. 2015;21:150-153.

52. Sirls LT, Foote JE, Kaufman JM, et al. Long term effects of FemSoft urethral insert for the management of female stress urinary incontinence. Int Urogynecol J Pelvic Floor Dysfunct. 2002;13:88-95.

53. United States Food and Drug Administration [webpage on the Internet]. Stress Urinary Incontinence (SUI). Available from: https://www.fda. gov/MedicalDevices/ucm284109.htm. Accessed August 7, 2017.

54. Maund E, Guski LS, Gøtzsche PC. Considering benefits and harms of duloxetine for treatment of stress urinary incontinence: a meta-analysis of clinical study reports. Can Med Assoc J. 2017;189:E194-E203.

55. Krammerer-Doak D, Svabik K, Bazi T. Variability in practice patterns in stress urinary incontinence and pelvic organ prolapse: results of an IUGA survey. Int Urogynecol J. 2017;28:735-744.

56. Atnip SD. Pessary use and management for prlvic organ prolapse. Obstet Gynecol Clin North Am. 2009;36:541-563.

57. Richter HE, Burgio KL, Brubaker L, et al. Continence pessary compared with behavioral therapy or combined therapy for stress incontinence: a randomized controlled trial. Obstet Gynecol. 2010;115:609-617.

58. Bettez M, Tu LM, Carlson K, Corcos J, Jolivet M, Bailley G. 2012 Update: guidelines for adult urinary incontinence collaborative consensus document for the Canadian Urological Association. Can Urol Assoc J. 2012;6:354-363.

59. Clemons JL, Aguilar VC, Tillinghast TA, Jackson ND, Myers DL. Patient satisfaction and changes in prolapse and urinary symptoms in women who were fitted successfully with a pessary for pelvic organ prolapse. Am J Obstet Gynecol. 2004;190:1025-1029.

60. Kenton K, Barber M, Wang L, et al. Pelvic floor symptoms improve similarly after pessary and behavioral treatment for stress incontinence. Female Pelvic Reconstr Surg. 2012;18:118-121.

61. Handa VL, Whitcomb E, Weidner AC, et al. Sexual function before and after non-surgical treatment for stress urinary incontinence. Female Pelvic Med Reconstr Surg. 2011;17:30-35.

62. Fernando RJ, Thakar S, Sultan AH, Shah SM, Jones PW. Effect of vaginal pessaries on symptom associated with pelvic organ prolapse. Obstet Gynecol. 2006;108:93-99.

63. Brincat C, Kenton K, Fitzgerald MP, Brubaker L. Sexual activity predicts continued pessary use. Am J Obstet Gynecol. 2004;191:198-200.

64. Schaffer J, Nager CW, Xiang F, et al. Predictors of success and satisfaction of nonsurgical therapy for stress urinary incontinence. Obstet Gynecol. 2012;120:91-97.

65. Lone F, Thakar R, Sultan AH. One-year prospective comparison of vaginal pessaries and surgery for pelvic organ prolapse using the validated ICIQ-VS and ICIQ_UI (SF) questionnaires. Int Urogynecol J. 2015;26:1305-1312.

66. Sullivan SA, Davidson ER, Bretschneider CE, Liberty AL, Geller EJ. Patient characteristics associated with treatment choice for pelvic organ prolapse and urinary incontinence. Int Urogynecol J. 2016;27: 811-816.

67. Bash KL. Review of vaginal pessaries. Obstet Gynecol Surv. 2000;55: 455-460.

68. Sarma S, Ying T, Moore KH. Long term vaginal ring pessary use: discontinuation rates and adverse events. BJOG. 2009;116:1715-1721. 
International Journal of Women's Health

Dovepress

\section{Publish your work in this journal}

The International Journal of Women's Health is an international, peerreviewed open-access journal publishing original research, reports, editorials, reviews and commentaries on all aspects of women's healthcare including gynecology, obstetrics, and breast cancer. The manuscript management system is completely online and includes

Submit your manuscript here: http://www.dovepress.com/international-journal-of-womens-health-journa a very quick and fair peer-review system, which is all easy to use. Visit http://www.dovepress.com/testimonials.php to read real quotes from published authors. 